\title{
Control of productivity of agrocenosis
}

\author{
Svetlana Didovich*, Tatiana Gorgulko, and Alexander Didovich \\ Research Institute of Agriculture of Crimea, 295493 Simferopol, Russia
}

\begin{abstract}
In this work, the authors used statistical processing of results of the long-term field several pieces of research by the method of multivariate analyze, factor analysis, and visualization of data with the use of the computer program Statistica 10. They created the multivariate Electronic Database for in-depth analysis and description of the effect of microbial preparations based on heterotrophic and phototrophic microorganisms on the efficiency of plant-microbial symbiotic systems in agrocenoses of legumes. Based on the field experiments on southern Chernozem in the steppe zone of the Crimea, the biological activity of the soil and the physiological and biochemical potential of soybean, pea, chickpea, peavine, and lentil were determined. The direction of microbiological and enzymatic processes in the rhizosphere was established, as well as interactive connections in the system "microorganisms - plants - soil". The use of microbial preparations had a greater impact $(2$ times, $\mathrm{p}<0.05)$ on the physiological and biochemical status of plants, crop structure, seed productivity, and grain quality. To a lesser extent, it influenced the biological activity of the soil in the agrocenosis of legumes. The advantage of using polyfunctional Cyanobacterial consortium in growing legumes for realizing the potential of plant-microbe interactions compared to monobacterization with Rhizobofit, fungi arbuscular mycorrhizae and biological products Rhizobofit, Phosfoenterin, and Biopolicyd was shown.
\end{abstract}

\section{Introduction}

Currently, environmentally friendly land use, bringing agriculture as close to natural analogues as possible, but maintaining high productivity, as well as the development of new farming systems and high-tech agriculture are gaining greater attention [1]. Biological nitrogen and symbiotic, associative and free-living microorganisms have a special place in this concept. They provide more than $70-90 \%$ of the nitrogen reserve in arable soils by fixing atmospheric nitrogen [2].

The stabilizing basis of farming systems is legumes. They enter into symbiosis with specific nodule bacteria, form nitrogen-fixing nodules and are able to assimilate $125-480 \mathrm{~kg} / \mathrm{ha}$ of air nitrogen in different soil and climatic conditions during vegetation [3]. Scientifically based share of legumes in the total structure of crops should be $20-40 \%$. About $50 \%$ of nitrogen fixed from the air remains in the soil with crop residues from the roots of perennial legumes. After annual legumes, about $20 \%$ remains. This significantly increases the yield of subsequent crops.

Nowadays, the existing understanding of the role of soil-microbiological processes and the effectiveness of the potential of plant-microbial interactions in agroecosystems has been significantly improved. The phenomenon of integration of u1075 genetic systems of microorganisms and plants, changes in phytohormonal and regulatory functions in the interaction of micro- and macro-partners of symbiosis, system control of organogenesis of nitrogen-fixing root nodule in legumes were discovered [4]. The influence of various pathogens on the microbiome (efficiency of beneficial microorganisms) [5], environmental conditions and soil composition [6, 7], plant varieties and genotypes (influence of root exudates with different biochemistry) $[8,9]$ were studied. Based on the knowledge of the fundamental mechanisms of interaction between plants and microorganisms, it is possible to determine the degree of influence of various factors and evaluate the productivity potential of the plant-microbe system.

The effectiveness of symbiotic nitrogen fixation in agrocenoses depends on the type and variety of legumes, rhizobia strain, soil type, agro- and meteorological conditions, fertilizers and plant protection products. The nitrogen-fixing potential of legume-rhizobial systems is genetically determined and depends on the complementarity of genotypes of phyto- and rhizobiasymbiont [10]. It is necessary to raise the genetic nitrogen-fixing potential of legume-rhizobial symbiosis to intensify symbiotic nitrogen fixation in modern farming systems.

However, there are still many issues concerning the functional activity of strains. They are bioagents of mono- and poly-strains biological preparations; their resistance in certain agro-climatic conditions to anthropogenic and natural stress factors; optimization of nutrition and protection of agricultural plants; search for ways to predict the effectiveness of agrocenoses, etc.

Assessment of the bio-potential of plant-microbial interaction and the search for ways to control the productivity of agrocenoses of legumes on southern

* Corresponding author: sv-alex.68@mail.ru 
Chernozem in the steppe zone of the Crimea was the aim of our research.

\section{Methods and conditions}

Research work was carried out in 2012-2016. Field studies of agrocenoses of five legumes (pea, chickpea, peavine, lentil, soybean) were carried out in the steppe zone of the Crimea on southern Chernozem in 20122014. The arable soil layer $(0-20 \mathrm{~cm})$ was characterized by high availability of exchangeable potassium and mobile phosphorus and low availability of easily hydrolyzed nitrogen. Agrochemical parameters of soils were determined using standard methods: humus by Tyurin, mobile phosphorus $\left(\mathrm{P}_{2} \mathrm{O}_{5}\right)$ and exchangeable potassium $\left(\mathrm{K}_{2} \mathrm{O}\right)$ by Machigin. The easily hydrolyzed nitrogen was determined according to GOST 26213-91 [11].

Before sowing, legume seeds were treated with microbial preparations based on the strains from the Crimean Collection of Microorganisms of Federal State Budget Scientific Institution "Research Institute of Agriculture of Crimea" (Simferopol) [12]. Strains of microorganisms were deposited in Russian Collection of Agricultural Microorganisms (RCAM) of FSBIS AllRussia Research Institute for Agricultural Microbiology RAS (Saint-Petersburg) [13], Russian National Collection of Industrial Microorganisms (VKPM) of Scientific Center "Kurchatov Institute" - Research Institute for Genetics and Selection of Industrial Microorganisms (Moscow) [14], Collection of Microalgae IPPAS and Cyanobacteria of the Institute of Plant Physiology RAS [15].

Microbial preparations for the experiments were made in the Department of Agricultural Microbiology of Federal State Budget Scientific Institution "Research Institute of Agriculture of Crimea" (Simferopol). Rhizobofit ( $\mathrm{R})$ is a microbial preparation based on specific symbiotic nitrogen-fixing nodule bacteria. Phosfoenterin $(\mathrm{Ph})$ is a preparation based on phosphatemobilizing strain Lelliottia nimipressuralis strain VKPM V-12783. Biopolicyd (B) is a microbial preparation based on the antagonist of phytopathogens strain Paenibacillus polymyxa $\mathrm{P}$. Arbuscular mycorrhizal fungi (AMF) is a preparation based on the fungi arbuscular mycorrhizae. Cyano-rhizobial consortium (CRC) is a microbial preparation based on a specific strain of rhizobia and nitrogen-fixing strain of cyanobacteria Nostoc linckia IPPAS B-2044 with stimulating activity.

The preparations were used in an amount of 1.5-2.0\% of the working solution by seed weight. AMF were introduced at a dose of $50 \mathrm{~g} / \mathrm{m}^{2}$ together with nodule bacteria [16]. Winter barley was the preceding crop. The experiments were repeated four times. The accounting area of the plot was $25 \mathrm{~m}^{2}$. Harvesting was carried out mechanically with recalculation on $100 \%$ purity and 14 $\%$ moisture of seeds [17].

During three phases of plant development (branching, flowering, ripening of beans), we analyzed the changes in the number of ecological and trophic groups of microorganisms, enzymatic activity, and intensity of the release of carbon dioxide in the rhizosphere. Symbiotic parameters were determined during the flowering phase of plants. The structure of the legume crop was evaluated. All results of field experiments were published in scientific journals $[18,19]$.

The Electronic Database (EDB) was developed in 2015-2016 to search for interactive links in the system "microorganisms - plants - soil" and to control the productivity of agrocenoses of legumes using effective symbiotic interactions. Mathematical and analytical processing of the research results was carried out by the method of multivariate exploration and factor analysis using the software Statistica 10.

\section{Results and discussion}

As a result of three-year research of biological activity of the soil and productivity of agrocenoses of legumes, a lot of experimental data has been accumulated. The data were collected, systematized and included in an Electronic Database for in-depth analysis and description of the effect of microbial preparations based on heterotrophic and phototrophic microorganisms on the efficiency of plant-microbial symbiotic systems in legume agrocenoses. The Electronic database (EDB) is implemented in Microsoft Excel 17 e-sheets. It structured set of parameters and characteristics of the state of agrocenoses of soybean, chickpea, pea, peavine, and lentil according to the phases of development of plants and years of research. It contains experimental data, calculation formulas, spreadsheets, algorithms for computing and accounting the reliability of the results, statistical matrix, etc. EDB was supported by the program Statistica 10.

The structure of EDB includes the following blocks:

1. Block of soil biological activity:

a) structural and functional diversity of the soil bacterial microbiota in the rhizosphere of legumes based on the ratio and the number of different ecological trophic groups of soil microorganisms: the number of bacteria which are using mineral forms, ammonificators, nitrogen-fixing bacteria, oligotrophic microorganisms, phosphate-mobilizing and cellulose-decomposing bacteria, micromycetes, actinomycetes in three phases of plant development: branching, flowering, maturation;

b) enzymatic activity of oxidoreductases in the rhizosphere of plants: catalase, peroxidase, polyphenol oxidase; hydrolase: invertase, phosphatase; the intensity of the release of carbon dioxide in three phases of plant development: branching, flowering, maturation;

c) the intensity and direction of microbiological and biochemical processes (coefficients of mineralization, oligotrophy, microbial transformation of organic matter, and humification) in the phases of plant development: branching, flowering, maturation.

2. Block of physiological and biochemical parameters and productivity of plants:

a) the oxidoreductase enzymes activity (catalase, peroxidase, polyphenol oxidase), the content of 
antioxidants (glutathione and ascorbic acid) in the phase of intensive plant development - flowering phase;

b) symbiotic efficiency (indicators of rhizobial and mycorrhizal symbiosis with plants) in the phase of intensive plant development - flowering phase;

c) data on crop structure, seed productivity, and legume grain quality.

The analysis of EDB data using multivariate exploration and factor analysis allowed establishing the degree of influence of factors on the potential of "plantsmicroorganisms-soil" in arid climatic conditions of the steppe Crimea.

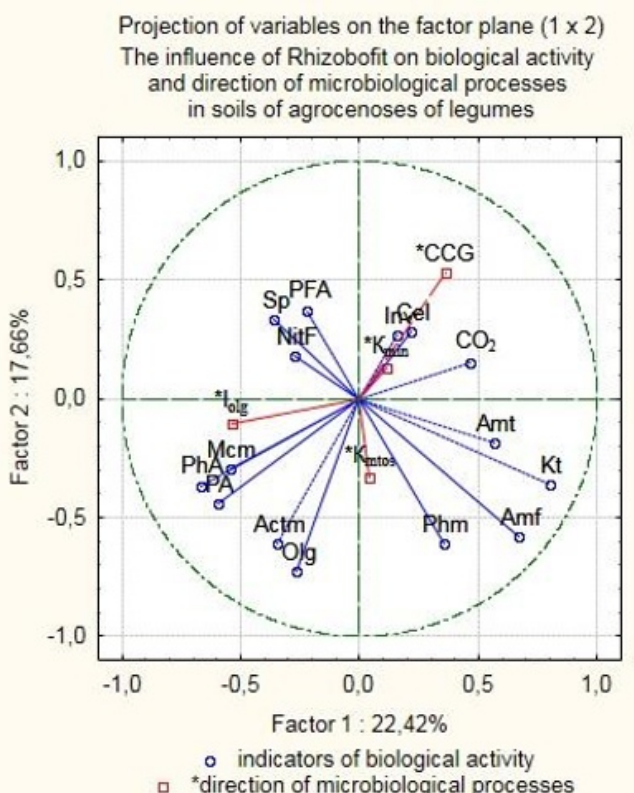

a

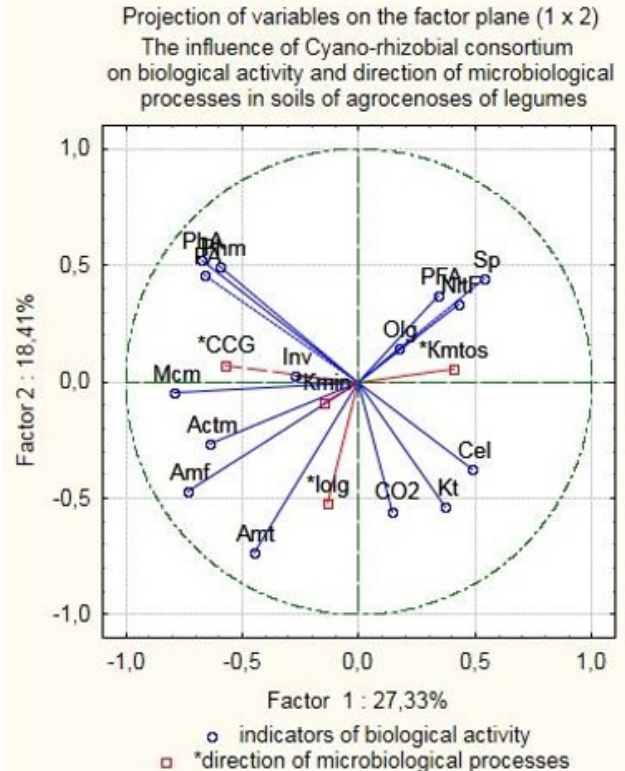

C
The advantage of the use of polyfunctional microbial preparations such as Cyano-rhizobial consortium and complex Rhizobofit, Phosfoenterin, Biopolicyd was found. They provided the maximum contribution of indicators of dynamics of biological activity of the soil (Fig. 1, a-d), physiological and biochemical parameters of plants, crop structure, seed productivity and grain quality (Fig. 2, a-d) in the agrocenoses of five legumes. This was shown on the base on the identified correlations ( $p<0.05)$ in comparison with monobacterization with Rhizobofit.

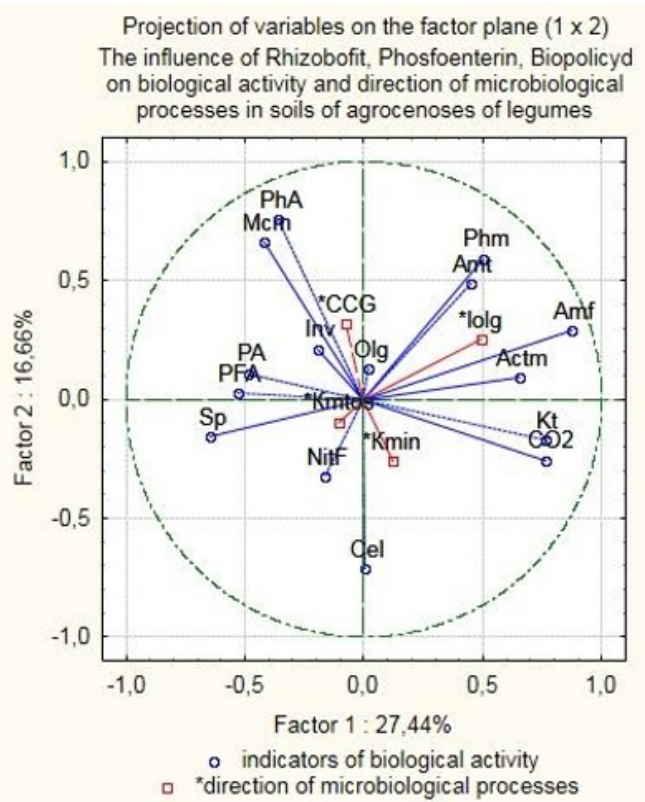

b

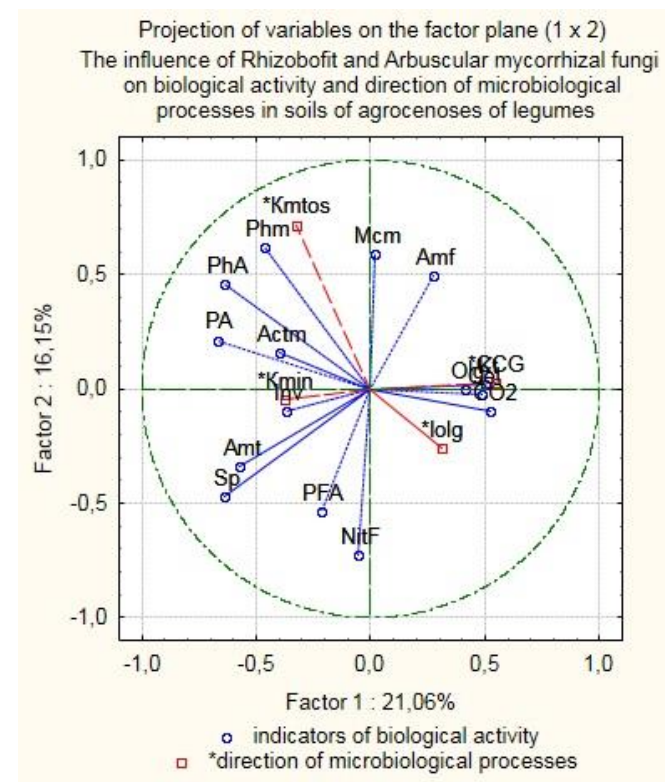

d

Fig. 1. Visual indicator of the relationships the between index of biological activity of soils in agrocenoses of leguminous crops and bacterization of plants ( $\mathrm{p}<0.05$ ): $\mathrm{a}$ - Rhizobofit, $\mathrm{b}$ - Rhizobofit, Phosfoenterin, Biopolicyd; $\mathrm{c}$ - Cyano-rhizobial consortium; $\mathrm{d}$ Rhizobofit, Arbuscular mycorrhizal fungi. 
Notes: the number of: Amt - bacteria which are using mineral forms, Amf - ammonificators, Olg -oligotrophic bacteria, NitFnitrogen-fixing bacteria, Phm - phosphate-mobilizing bacteria, Cel - cellulose-decomposing bacteria, Mcm - micromycetes, Actm actinomycetes, $\mathrm{Sp}$ - bacteria which form spores; PFA - polyphenoloxidase activity, PA - peroxidase activity, Kt - activity of catalase, Inv - activity of invertase, $\mathrm{PhA}$ - activity of phosphatase, $\mathrm{CO}_{2}$ - the intensity of the release of carbon dioxide, ${ }^{*} \mathrm{Kmin}-$ coefficients of mineralization, * $\mathrm{Iolg}$ - coefficients of oligotrophy, ${ }^{*} \mathrm{Kmtos}$ - coefficients of microbial transformation of organic matter, *CCG - coefficients of humification.

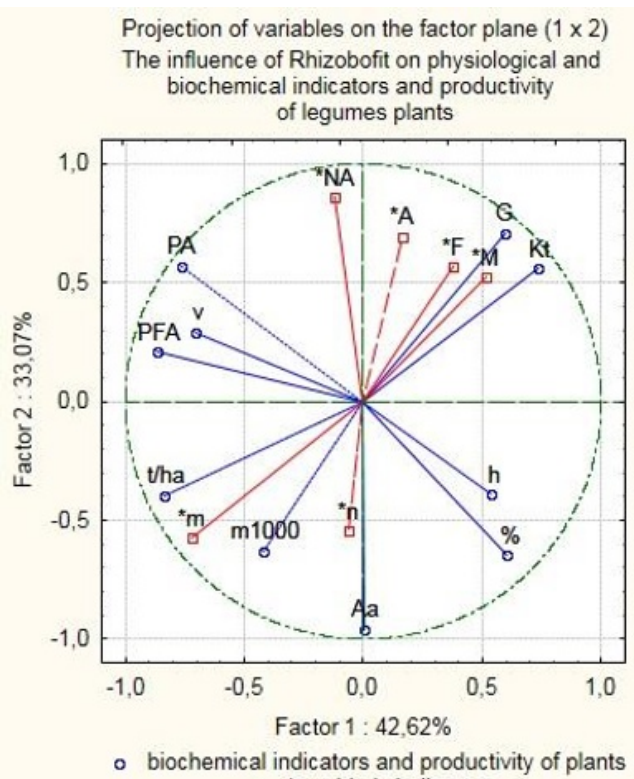

口 *symbiotic indicators

a

Projection of variables on the factor plane $(1 \times 2)$

The influence of Cyano-rhizobial consortium on physiological and biochemical indicators and productivity of legumes plants

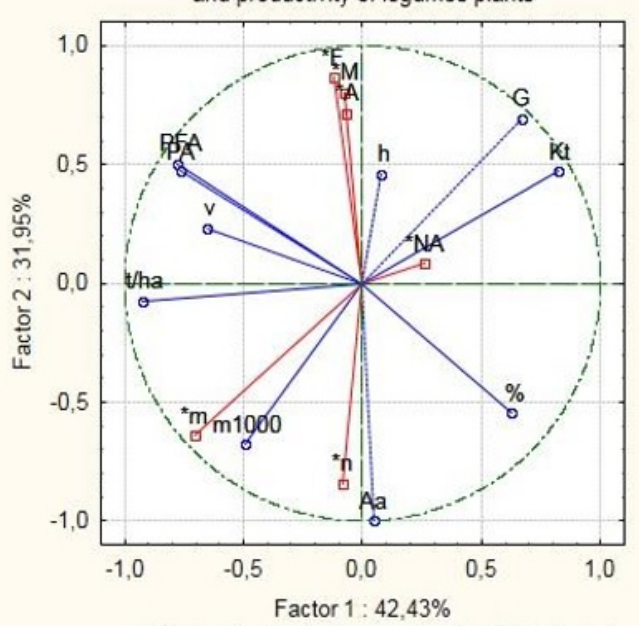

- biochemical indicators and productivity of plants 口 "symbiotic indicators

C

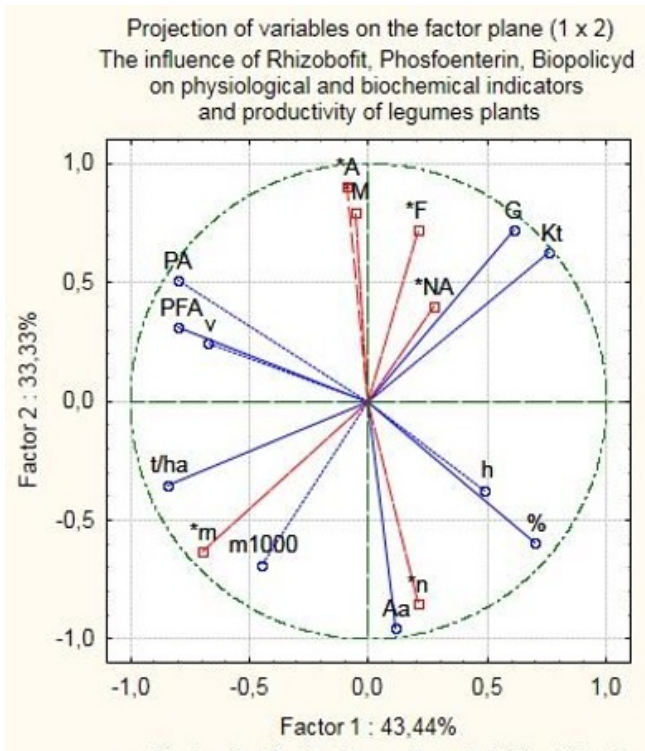

- biochemical indicators and productivity of plants 口 *symbiotic indicators

b

Projection of variables on the factor plane $(1 \times 2)$ The influence of Rhizobofit and Arbuscular mycorrhizal fungi on physiological and biochemical indicators and productivity of legumes plants

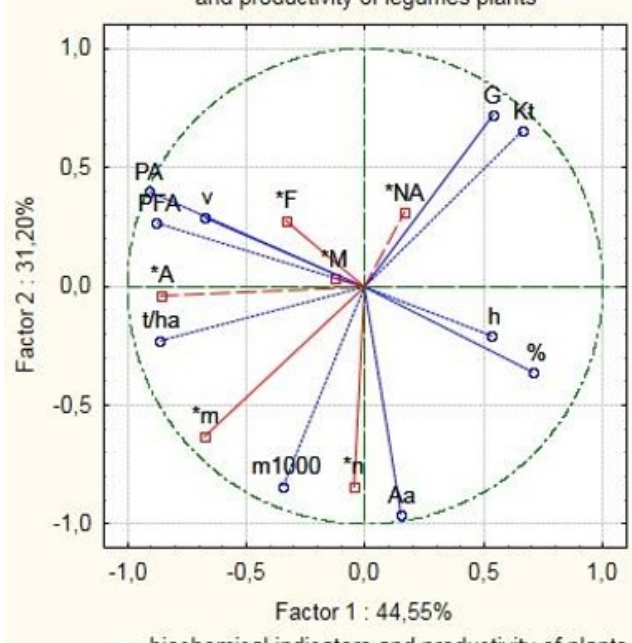

- biochemical indicators and productivity of plants 口 *symbiotic indicators

d

Fig. 2. Visual indicator of the relationships between the index of physiological, biochemical parameters of plants, crop structure, seed productivity, grain quality in agrocenoses of legumes and bacterization of plants $(p<0.05)$ : $a-$ Rhizobofit, $b-$ Rhizobofit, Phosfoenterin, Biopolicyd; c-Cyano-rhizobial consortium; $d$ - Rhizobofit, Arbuscular mycorrhizal fungi.

Notes: PFA - polyphenoloxidase activity in the leaves of a plant, PA - peroxidase activity in the leaves of a plant, Kt - activity of catalase in the leaves of a plant, $\mathrm{Aa}$ - content of ascorbic acid in the leaves of a plant, $\mathrm{G}$ - content of glutathione in the leaves of a plant, $\mathrm{h}$ - height of plants, m1000 - the mass of 1000 grains, $\mathrm{v}$ - density of plants before harvest, t/ha - yield, *n - number of nitrogen-fixing root nodules, *m - mass of root nitrogen-fixing nodules, *NA - nitrogenase activity of root nitrogen-fixing nodules, ${ }^{*} \mathrm{~F}-$ the frequency of occurrence of AMF in root, ${ }^{*} \mathrm{M}$ - the intensity of mycorrhization in root, ${ }^{*} \mathrm{~A}-$ number of arbusculas of mycorrhizal fungi in root. 
Figures 1-2 show how well each variable is reproduced by the current set of factors. The closer a variable is to the unit circle, the smaller the spread of variables, and the larger the clusters, the better it is reproduced in the coordinate system. We analyzed the structure of nonlinear relationships to identify factor loads on the system of agrocenoses of all legumes and established the maximum influence of factors on the functioning of symbiotic systems with the plant (Table $1)$.

The use of preparations had a greater impact (2 times) on the physiological and biochemical status of plants, crop structure, seed productivity, and grain quality. To a lesser extent, it influenced the biological activity of the soil in agrocenosis. Between the total influences of the factors, the minimum difference (29\%) was identified after using Cyano-rhizobial consortium compared to Rhizobofit - $36 \%$, Rhizobofit, Phosfoenterin, Biopolicyd - $33 \%$, Rhizobofit and Arbuscular mycorrhizal fungi - $39 \%$. This may indicate a more balanced potential of plant-microbial interaction after using Cyano-rhizobial consortium. We established the polyfunctional effect of this consortium on biological activity, the direction of microbiological and biochemical processes in the soil, as well as the productivity of legumes. This may indicate the possibility of directed regulation of the productivity of agrocenoses of legumes and their maximum realization of their biological potential in the system "microorganisms-plants-soil".

Table 1. Main factor loads on soil biological activity and physiological and biochemical status of plants in agrocenoses of legumes

\begin{tabular}{|c|c|c|c|c|c|c|}
\hline \begin{tabular}{|c|} 
Variant of the \\
experiment
\end{tabular} & Indicators & \begin{tabular}{|c|}
$\%$ of \\
the factor ${ }^{\mathrm{a}}$ of influence \\
and on the indicators
\end{tabular} & $\begin{array}{c}\% \text { of } \\
\text { the factor }{ }^{\mathrm{b}} \text { of influence } \\
\text { and on the indicators }\end{array}$ & $\begin{array}{c}\Sigma \text { influence } \\
\text { of factors, } \\
\% \\
\end{array}$ & \begin{tabular}{|c|}
$\begin{array}{c}\text { Average } \\
\text { on the } \\
\text { factors, } \%\end{array}$ \\
\end{tabular} & $\begin{array}{c}\text { Difference on } \\
\text { the factors, } \\
\% \\
\end{array}$ \\
\hline \multirow[b]{2}{*}{$\mathrm{R}$} & Soil biological activity & 22.42 & 17.66 & 40.08 & \multirow[b]{2}{*}{57.89} & \multirow[b]{2}{*}{35.61} \\
\hline & $\begin{array}{l}\text { Physiological and biochem. } \\
\text { plant status and productivity }\end{array}$ & 42.62 & 33.07 & 75.69 & & \\
\hline \multirow[b]{2}{*}{$\mathrm{R}+\mathrm{Ph}+\mathrm{B}$} & Soil biological activity & 27.44 & 16.66 & 44.1 & \multirow[b]{2}{*}{60.34} & \multirow[b]{2}{*}{32.67} \\
\hline & $\begin{array}{l}\text { Physiological and biochem. } \\
\text { plant status and productivity }\end{array}$ & 43.44 & 33.33 & 76.77 & & \\
\hline \multirow[b]{2}{*}{$\mathrm{CRC}$} & Soil biological activity & 27.33 & 18.41 & 45.74 & \multirow[b]{2}{*}{60.06} & \multirow[b]{2}{*}{28.64} \\
\hline & $\begin{array}{l}\text { Physiological and biochem. } \\
\text { plant status and productivity }\end{array}$ & 42.43 & 31.95 & 74.38 & & \\
\hline \multirow[b]{2}{*}{$\mathrm{R}+\mathrm{AMF}$} & Soil biological activity & 21.06 & 16.15 & 37.21 & \multirow[b]{2}{*}{56.48} & \multirow[b]{2}{*}{38.54} \\
\hline & $\begin{array}{l}\text { Physiological and biochem. } \\
\text { plant status and productivity }\end{array}$ & 44.55 & 31.2 & 75.75 & & \\
\hline
\end{tabular}

Notes: R - Rhizobofit, Ph - Phosfoenterin, B - Biopolicyd; CRC - Cyano-rhizobial consortium; AMF - Arbuscular mycorrhizal fungi; a (b) - a kit of factors clustered by the degree of importance and influence on the system of agrocenosis $(p<0.05)$.

\section{Conclusion}

Thus, the analytical assessment of the biological potential of agrocenoses of five legumes was carried out for the first time on the basis of long-term research in soil and climatic conditions of the steppe zone of the Crimea.

The use of microbial preparations had a greater impact ( 2 times) on the physiological and biochemical status of plants, crop structure, seed productivity, and grain quality and to a lesser extent influenced the biological activity of the soil in agrocenosis.

The advantage of using polyfunctional Cyanobacterial consortium in the cultivation of leguminous crops to realize the potential of systems "microorganisms - plants - soil" in compared to bacterization with Rhizobofit, Arbuscular mycorrhizal fungi and biological preparations Rhizobofit, Phosfoenterin, and Biopolicyd was shown.

\section{References}

1. V.I. Kiryushin, Bull. of the Russ. Agricult. Sci. 4, 710 (2019) DOI: https://doi.org/10.30850/vrsn/2019/4/7-10

2. I.A. Tikhonovich, A.A. Zavalin, Fertility 5(92), 28-32 (2016)

3. A.A. Zavaliv, N.S. Almetov, V.V. Berdnikov, G.G. Blagoveshchenskaya, Eurasian Soil Science 6, 28-37 (2010)

4. I.A. Tikhonovich, N.A. Provorov, Russ. J. Genet.: Appl. Res. 2(5), 353-356 (2012) Retrieved from: https://doi.org/10.1134/S2079059712050073

5. B.E. Wiggins, L.L. Kinkel, Phytopathology 95, 178-185 (2005) DOI: 10.1094/PHYTO-95-0178

6. Chang Fu Tian et al., Proc. Natl. Acad. Sci. U.S.A. (2012) DOI: 10.1073/pnas.1120436109

7. Clare Gough et al., TRPLSC 1072, 1-9 (2012) DOI: 10.1016/j.tplants.2013.06.001

8. D. S. Lundberg et al., Nature 488, 86-90 (2012) DOI: 10.1038 / nature 11237 
9. A.I. Shaposhnikov, Y.V. Pukhalsky, L.V. Kravchenko, A.A. Belimov, The Role of root exudation in trophic interactions of plants with rhizosphere microorganisms (Inform-Navigator, St. Petersburg, 2016)

10. N.A. Provorov, I.A. Tikhonovich, Ecolog. genet. 17(1), 5-10 (2019) Retrieved from: https://doi.org/10.17816/ecogen1715-10

11. GOST 26213-91 Soils. Methods for determination of organic matter (Publisher of standards, Moscow, 1992) Retrieved from: http://docs.cntd.ru/document/1200023481

12. Collection of Microorganisms of Federal State Budget Scientific Institution "Research Institute of Agriculture of Crimea" USI: CCM FSBSI "RIAC", Sci. and Technol. Infrastruct. of the Russ. Federat. Centers for Collect. Use of Sci. Equipm. and Unique Sci. Installations (2019) Retrieved from: http://ckprf.ru/usu/507484/

13. Russian Collection of Agricultural Microorganisms (RCAM) of FSBIS All-Russia Research Institute for Agricultural Microbiology RAS, Sci. and Technol. Infrastruct. of the Russ. Federat. Centers for Collect. Use of Sci. Equipment and Unique Sci. Installations (2019) Retrieved from: https://arriam.ru/kollekciyakul-tur1/
14. Russian National Collection of Industrial Microorganisms (VKPM) of Scientific Center "Kurchatov Institute" - Research Institute for Genetics and Selection of Industrial Microorganisms, Sci. and Technol. Infrastruct. of the Russ. Federat. Centers for Collect. Use of Sci. Equipment and Unique Sci. Installations (2019) Retrieved from: http://ckp-rf.ru/usu/73594/

15. Collection of Microalgae and Cyanobacteria IPPAS of Institute of Plant Physiology RAS (USI CMC IPPAS IPP RAS), Sci. and Technol. Infrastruct. of the Russ. Federat. Centers for Collect. Use of Sci. Equipment and Unique Sci. Installations (2019) Retrieved from: http://ckp-rf.ru/usu/507532/

16. V.V. Volkogon, The methodology and practice of application of microbial substances in the cultivation of agricultural plants (Agrarna nauka, Kiev, 2011)

17. B.A. Dospekhov, Methods of field research (Moscow, 2011)

18. S.V. Didovich, T.V. Gorgulko, R.A. Kulinich, S.F. Abdurashitov, E.L. Turina, A.N. Didovich, Bull. of Uman National Univer. of Horticult. 2, 14-18 (2014)

19. E.L. Turina, S.V. Didovich, R.A. Kulinich, A.N. Didovich, Agroecolog. J. 3, 82-87 (2015) 